\title{
Strong convergence theorem for quasi- $\phi$-asymptotically nonexpansive mappings in the intermediate sense in Banach spaces
}

\section{Zhaoli Ma ${ }^{1}$, Lin Wang ${ }^{2 *}$ and Shih-sen Chang ${ }^{2}$}

\section{"Correspondence:}

WL64mail@yahoo.com.cn

${ }^{2}$ College of Statistics and

Mathematics, Yunnan University of

Finance and Economics, Kunming,

Yunnan 650021, P.R. China

Full list of author information is

available at the end of the article

\begin{abstract}
In this paper, we modify Halpern and Mann's iterations for finding a fixed point of an infinite family of quasi- $\phi$-asymptotically nonexpansive mappings in the intermediate sense in Banach spaces. We prove a strong convergence theorem of the iterative sequence generated by the proposed iterative algorithm in a uniformly smooth and strictly convex Banach space which also enjoys the Kadec-Klee property. The results presented in this paper improve and extend some recent corresponding results. MSC: $47 \mathrm{H} 09 ; 47 \mathrm{~J} 25$
\end{abstract}

Keywords: quasi- $\phi$-asymptotically nonexpansive mappings in the intermediate sense; strong convergence; fixed point; generalized projection

\section{Introduction}

Let $E$ be a real Banach space with the dual space $E^{*}$ and let $C$ be a nonempty closed convex subset of $E$. We denote by $R^{+}$and $R$ the set of all nonnegative real numbers and the set of all real numbers, respectively. Also, we denote by $J$ the normalized duality mapping from $E$ to $2^{E^{*}}$ defined by

$$
J x=\left\{x^{*} \in E^{*}:\left\langle x, x^{*}\right\rangle=\|x\|^{2}=\left\|x^{*}\right\|^{2}\right\}, \quad \forall x \in E,
$$

where $\langle\cdot, \cdot\rangle$ denotes the generalized duality pairing. Recall that if $E$ is smooth, then $J$ is single-valued and norm-to-weak* continuous, and that if $E$ is uniformly smooth, then $J$ is uniformly norm-to-norm continuous on bounded subsets of $E$. We shall denote by $J$ the single-valued duality mapping.

A Banach space $E$ is said to be strictly convex if $\frac{\|x+y\|}{2} \leq 1$ for all $x, y \in U=\{z \in E:\|z\|=1\}$ with $x \neq y$. $E$ is said to be uniformly convex if, for each $\varepsilon \in(0,2]$, there exists $\delta>0$ such that $\frac{\|x+y\|}{2} \leq 1-\delta$ for all $x, y \in U$ with $\|x-y\| \geq \varepsilon$. $E$ is said to be smooth if the limit

$$
\lim _{t \rightarrow 0} \frac{\|x+t y\|-\|x\|}{t}
$$

exists for all $x, y \in U$. $E$ is said to be uniformly smooth if the above limit exists uniformly in $x, y \in U$.

C 2013 Ma et al.; licensee Springer. This is an Open Access article distributed under the terms of the Creative Commons Attribution License (http://creativecommons.org/licenses/by/2.0), which permits unrestricted use, distribution, and reproduction in any medium, provided the original work is properly cited. 
Remark 1.1 The following basic properties of a Banach space $E$ can be found in [1]:

(i) If $E$ is a uniformly smooth Banach space, then $J$ is uniformly continuous on each bounded subset of $E$.

(ii) If $E$ is a reflective and strictly convex Banach space, then $J^{-1}$ is norm-to-weak* continuous.

(iii) If $E$ is a smooth, reflective and strictly convex Banach space, then the normalized duality mapping $J: E \rightarrow 2^{E^{*}}$ is single-valued, one-to-one and surjective.

(iv) A Banach space $E$ is uniformly smooth if and only if $E^{*}$ is uniformly convex. If $E$ is uniformly smooth, then it is smooth and reflective.

(v) Each uniformly convex Banach space $E$ has the Kadec-Klee property, that is, for any sequence $\left\{x_{n}\right\} \subset E$, if $x_{n} \rightarrow x \in E$ and $\left\|x_{n}\right\| \rightarrow\|x\|$, then $x_{n} \rightarrow x$. See [1,2] for more details.

(vi) If $E$ is a strictly convex and reflective Banach space with a strictly convex dual $E^{*}$ and $J^{*}: E^{*} \rightarrow E$ is the normalized duality mapping in $E^{*}$, then $J^{-1}=J^{*}, J J^{*}=I_{E^{*}}$ and $J^{*} J=I_{E}$

Next, we assume that $E$ is a smooth, reflective and strictly convex Banach space. Consider the functional defined as in $[3,4]$ by

$$
\phi(x, y)=\|x\|^{2}-2\langle x, J y\rangle+\|y\|^{2}, \quad \forall x, y \in E .
$$

It is clear that in a Hilbert space $H,(1.2)$ reduces to $\phi(x, y)=\|x-y\|^{2}, \forall x, y \in H$.

It is obvious from the definition of $\phi$ that

$$
(\|x\|-\|y\|)^{2} \leq \phi(x, y) \leq(\|x\|+\|y\|)^{2}, \quad \forall x, y \in E,
$$

and

$$
\phi\left(x, J^{-1}(\lambda J y+(1-\lambda) J z)\right) \leq \lambda \phi(x, y)+(1-\lambda) \phi(x, z), \quad \forall x, y \in E .
$$

Following Alber [3], the generalized projection $\Pi_{C}: E \rightarrow C$ is defined by

$$
\Pi_{C}(x)=\underset{y \in C}{\operatorname{arginf}} \phi(y, x), \quad \forall x \in E
$$

That is, $\Pi_{C} x=\bar{x}$, where $\bar{x}$ is the unique solution to the minimization problem $\phi(\bar{x}, x)=$ $\inf _{y \in C} \phi(y, x)$.

The existence and uniqueness of the operator $\Pi_{C}$ follows from the properties of the functional $\phi(x, y)$ and strict monotonicity of the mapping $J$ (see, e.g., [1-5]). In a Hilbert space $H, \Pi_{C}=P_{C}$.

Let $H$ be a real Hilbert space, let $D$ be a nonempty subset of $H$, and let $T: D \rightarrow D$ be a nonlinear mapping. The symbol $F(T)$ stands for the fixed point set of $T$. Recall the following. $T$ is said to be nonexpansive if

$$
\|T x-T y\| \leq\|x-y\|, \quad \forall x, y \in D .
$$

$T$ is said to be quasi-nonexpansive if $F(T) \neq \emptyset$ and

$$
\|p-T y\| \leq\|p-y\|, \quad \forall p \in F(T), \forall y \in D .
$$


$T$ is said to be asymptotically nonexpansive if there exists a sequence $\left\{\mu_{n}\right\} \subset[0, \infty)$ with $\mu_{n} \rightarrow 0$ as $n \rightarrow \infty$ such that

$$
\left\|T^{n} x-T^{n} y\right\| \leq\left(1+\mu_{n}\right)\|x-y\|, \quad \forall x, y \in D, \forall n \geq 1 .
$$

The class of asymptotically nonexpansive mappings was introduced by Goebel and Kirk [6]. Since 1972, a host of authors have studied the convergence of iterative algorithms for such a class of mappings.

$T$ is said to be asymptotically quasi-nonexpansive if $F(T) \neq \emptyset$ and there exists a sequence $\left\{\mu_{n}\right\} \subset[0, \infty)$ with $\mu_{n} \rightarrow 0$ as $n \rightarrow \infty$ such that

$$
\left\|p-T^{n} y\right\| \leq\left(1+\mu_{n}\right)\|p-y\|, \quad \forall p \in F(T), \forall y \in D, \forall n \geq 1 .
$$

Let $C$ be a nonempty closed convex subset of $E$, and let $T$ be a mapping from $C$ into itself. A point $p \in C$ is called an asymptotically fixed point of $T$ [7] if there exists a sequence $\left\{x_{n}\right\} \subset C$ such that $x_{n} \rightarrow p$ and $\left\|x_{n}-T x_{n}\right\| \rightarrow 0$. The set of asymptotical fixed points of $T$ will be denoted by $\widehat{F}(T)$. A point $p \in C$ is said to be a strong asymptotic fixed point of $T$, if there exists a sequence $\left\{x_{n}\right\} \subset C$ such that $x_{n} \rightarrow p$ and $\left\|x_{n}-T x_{n}\right\| \rightarrow 0$. The set of strong asymptotical fixed points of $T$ will be denoted by $\widetilde{F}(T)$.

A mapping $T: C \rightarrow C$ is said to be relatively nonexpansive [8-10] if $F(T) \neq \emptyset, F(T)=$ $\widehat{F}(T)$ and $\phi(p, T x) \leq \phi(p, x), \forall x \in C, p \in F(T)$.

A mapping $T: C \rightarrow C$ is said to be relatively asymptotically nonexpansive if

$$
\begin{aligned}
& F(T) \neq \emptyset, \quad F(T)=\widehat{F}(T) \quad \text { and } \\
& \phi\left(p, T^{n} x\right) \leq\left(1+\mu_{n}\right) \phi(p, x), \quad \forall x \in C, p \in F(T),
\end{aligned}
$$

where $\left\{\mu_{n}\right\} \subset[0, \infty)$ is a sequence such that $\mu_{n} \rightarrow 0$ as $n \rightarrow \infty$.

A mapping $T: C \rightarrow C$ is said to be quasi- $\phi$-nonexpansive if $F(T) \neq \emptyset$ and $\phi(p, T x) \leq$ $\phi(p, x), \forall x \in C, p \in F(T)$.

A mapping $T: C \rightarrow C$ is said to be quasi- $\phi$-asymptotically nonexpansive if $F(T) \neq \emptyset$, and there exists a real sequence $\left\{\mu_{n}\right\} \subset[0, \infty)$ with $\mu_{n} \rightarrow 0$ as $n \rightarrow \infty$ such that

$$
\phi\left(p, T^{n} x\right) \leq\left(1+\mu_{n}\right) \phi(p, x), \quad \forall n \geq 1, x \in C, p \in F(T) .
$$

Remark 1.2 From the definition, it is easy to know that

(i) Each relatively nonexpansive mapping is closed;

(ii) The class of quasi- $\phi$-asymptotically nonexpansive mappings contains properly the class of quasi- $\phi$-nonexpansive mappings as a subclass, but the converse is not true;

(iii) The class of quasi- $\phi$-nonexpansive mappings contains properly the class of relatively nonexpansive mappings as a subclass, but the converse may be not true. (See [11-15] for more details.)

Asymptotically (quasi-)nonexpansive mappings in the intermediate sense were first considered by Bruck et al. [16]. Very recently Qin and Wang [17] introduced the concept of the asymptotically (quasi-) $\phi$-nonexpansive mappings in the intermediate sense as follows: 
(1) $T$ is said to be asymptotically nonexpansive in the intermediate sense if it is continuous and the following inequality holds:

$$
\limsup _{n \rightarrow \infty} \sup _{x, y \in C}\left(\left\|T^{n} x-T^{n} y\right\|-\|x-y\|\right) \leq 0
$$

It is worth mentioning that the class of asymptotically nonexpansive in the intermediate sense mappings may not be Lipschitzian continuous; see $[16,18,19]$.

(2) $T$ is said to be asymptotically quasi-nonexpansive in the intermediate sense if $F(T) \neq$ $\emptyset$ and the following inequality holds:

$$
\limsup _{n \rightarrow \infty} \sup _{p \in F(T), y \in C}\left(\left\|p-T^{n} y\right\|-\|p-y\|\right) \leq 0
$$

(3) $T$ is said to be an asymptotically $\phi$-nonexpansive mapping in the intermediate sense if and only if

$$
\limsup _{n \rightarrow \infty} \sup _{x, y \in C}\left(\phi\left(T^{n} x, T^{n} y\right)-\phi(x, y)\right) \leq 0 .
$$

(4) $T: C \rightarrow C$ is said to be quasi- $\phi$-asymptotically nonexpansive mapping in the intermediate sense if and only if $F(T) \neq \emptyset$ and

$$
\limsup _{n \rightarrow \infty} \sup _{p \in F(T), x \in C}\left(\phi\left(p, T^{n} x\right)-\phi(p, x)\right) \leq 0
$$

Remark 1.3 The asymptotically (quasi-) $\phi$-nonexpansive mapping in the intermediate sense is a generalization of the asymptotically (quasi-)nonexpansive mapping in the intermediate sense in the framework of Banach spaces.

Definition 1.4 An infinite family of mappings $\left\{T_{i}\right\}_{i=1}^{\infty}: C \rightarrow C$ is said to be uniformly quasi- $\phi$-asymptotically nonexpansive in the intermediate sense if $\bigcap_{i=1}^{\infty} F\left(T_{i}\right) \neq \emptyset$ for each $i \geq 1$ and

$$
\limsup _{n \rightarrow \infty} \sup _{p \in F\left(T_{i}\right), x \in C}\left(\phi\left(p, T_{i}^{n} x\right)-\phi(p, x)\right) \leq 0 .
$$

If we define

$$
\xi_{n}=\max \left\{0, \sup _{p \in F\left(T_{i}\right), x \in C}\left(\phi\left(p, T_{i}^{n} x\right)-\phi(p, x)\right)\right\}
$$

then $\xi_{n} \rightarrow 0$ as $n \rightarrow \infty$. It follows that (1.16) is reduced to

$$
\phi\left(p, T_{i}^{n} x\right) \leq \phi(p, x)+\xi_{n}, \quad \forall p \in F\left(T_{i}\right), \forall x \in C, \forall n \geq 1
$$

Many problems in nonlinear analysis can be reformulated as a problem of finding a fixed point of a nonexpansive mapping. In 1953, Mann [20] introduced the iteration as follows: a sequence $\left\{x_{n}\right\}$ defined by

$$
x_{n+1}=\alpha_{n} x_{n}+\left(1-\alpha_{n}\right) T x_{n},
$$


where the initial guess $x_{1} \in C$ is arbitrary and $\left\{a_{n}\right\}$ is a real sequence in [0,1]. It is known that under appropriate settings the sequence $\left\{x_{n}\right\}$ converges weakly to a fixed point of $T$. However, for nonexpansive mappings, even in a Hilbert space, the Mann iteration may fail to converge strongly; for example, see [21].

Some attempts to construct the iteration method guaranteeing the strong convergence have been made. For example, Halpern [22] proposed the following so-called Halpern iteration:

$$
x_{n+1}=\alpha_{n} u+\left(1-\alpha_{n}\right) T x_{n},
$$

where $u \in C$ is fixed, $x_{1} \in C$ is arbitrarily chosen and $\left\{a_{n}\right\}$ is a real sequence in $[0,1]$.

Recently, Nilsrakoo and Saejung [23] modified Halpern and Mann's iterations introduced the following iteration to find a fixed point of the relatively nonexpansive mappings in the Banach space:

$$
x_{n+1}=\Pi_{C} J^{-1}\left(\alpha_{n} J u+\left(1-\alpha_{n}\right)\left(\beta_{n} J x_{n}+\left(1-\beta_{n}\right) J T x_{n}\right)\right) .
$$

They proved that $\left\{x_{n}\right\}$ converges strongly to $\Pi_{F(T)} u$, where $\left\{\alpha_{n}\right\},\left\{\beta_{n}\right\}$ are sequences in $(0,1), \Pi_{F(T)}$ is the generalized projection from $E$ onto $F(T)$.

Iteration methods for approximating fixed points of asymptotically nonexpansive mappings, quasi- $\phi$-nonexpansive mapping, quasi- $\phi$-asymptotically nonexpansive mapping have been further studied by authors (see, e.g., [6, 24-29]).

Quite recently, Qin and Wang [17] introduced the following iterative scheme to find a fixed point of the quasi- $\phi$-asymptotically nonexpansive mappings in the intermediate sense in a reflective, strictly convex and smooth Banach space such that both $E$ and $E^{*}$ have the Kadec-Klee property:

$$
\left\{\begin{array}{l}
x_{0} \in E \quad \text { chosen arbitrarily, } \\
C_{(1, i)}=C \\
C_{1}=\bigcap_{i \in \Lambda} C_{(1, i)}, \\
x_{1}=\Pi_{C_{1}} x_{0} \\
C_{(n+1, i)}=\left\{u \in C_{(n, i)}: \phi\left(x_{n}, T_{i}^{n} x_{n}\right) \leq 2\left\langle x_{n}-u, J x_{n}-J T_{i}^{n} x_{n}\right\rangle+\xi_{(n, i)}\right\}, \\
C_{n+1}=\bigcap_{i \in \Lambda} C_{(n+1, i)}, \\
x_{n+1}=\Pi_{C_{n+1}} x_{0}, \quad \forall n \geq 0,
\end{array}\right.
$$

where

$$
\xi_{(n, i)}=\max \left\{0, \sup _{p \in F\left(T_{i}\right), x \in C}\left(\phi\left(p, T_{i}^{n} x\right)-\phi(p, x)\right)\right\} .
$$

They proved that the sequence $\left\{x_{n}\right\}$ converges strongly to $\bar{x}=\Pi_{\bigcap_{i \in \Lambda} F\left(T_{i}\right)} x_{0}$.

Inspired and motivated by the recent work of Bruck [16], Qin and Wang [17], Nilsrakoo and Saejung [23], Chang et al. [24], etc., in this paper, we modify Halpern and Mann's iterations for finding a fixed point of an infinite family of quasi- $\phi$-asymptotically nonexpansive mappings in the intermediate sense in Banach spaces. We prove a strong convergence theorem of the iterative sequence generated by the proposed iterative algorithm in 
a uniformly smooth and strictly convex Banach space with the Kadec-Klee property. The results presented in this paper improve and extend some recent corresponding results.

\section{Preliminaries}

Throughout this paper, let $E$ be a real Banach space with the dual space $E^{*}$ and let $C$ be a nonempty closed convex subset of $E$. We denote the strong convergence, weak convergence of a sequence $\left\{x_{n}\right\}$ to a point $x \in E$ by $x_{n} \rightarrow x, x_{n} \rightarrow x$, respectively, and $F(T)$ is the fixed point set of a mapping $T$.

Lemma 2.1 [30] Let E be a real uniformly smooth and strictly convex Banach space with the Kadec-Klee property, and let $C$ be a nonempty closed convex subset of E. Let $\left\{x_{n}\right\}$ and $\left\{y_{n}\right\}$ be two sequences in $C$ such that $x_{n} \rightarrow p$ and $\phi\left(x_{n}, y_{n}\right) \rightarrow 0$, where $\phi$ is the functional defined by (1.2), then $y_{n} \rightarrow p$.

Lemma 2.2 [3] Let E be a smooth, strictly convex and reflective Banach space and let $C$ be a nonempty closed convex subset of $E$. Then the following conclusions hold:

(a) $\phi\left(x, \Pi_{C} y\right)+\phi\left(\Pi_{C} y, y\right) \leq \phi(x, y), \forall x \in C, y \in E$;

(b) If $x \in E$ and $z \in C$, then $z=\Pi_{C} x$ iff $\langle z-y, J x-J z\rangle \geq 0, \forall y \in C$;

(c) For $x, y \in E, \phi(x, y)=0$ if and only if $x=y$.

Lemma 2.3 [31] Let E be a uniformly convex Banach space, $r$ be a positive number and $B_{r}(0)$ be a closed ball of $E$. Then, for any sequence $\left\{x_{i}\right\}_{i=1}^{\infty} \subset B_{r}(0)$ and for any sequence $\left\{\lambda_{i}\right\}_{i=1}^{\infty}$ of positive numbers with $\sum_{n=1}^{\infty} \lambda_{n}=1$, there exists a continuous, strictly increasing and convex function $g:[0,2 r] \rightarrow[0, \infty), g(0)=0$ such that for any positive integer $i \neq 1$, the following holds:

$$
\left\|\sum_{n=1}^{\infty} \lambda_{n} x_{n}\right\|^{2} \leq \sum_{n=1}^{\infty} \lambda_{n}\left\|x_{n}\right\|^{2}-\lambda_{1} \lambda_{i} g\left(\left\|x_{1}-x_{i}\right\|\right) .
$$

\section{Main results}

Theorem 3.1 Let $C$ be a nonempty, closed and convex subset of a uniformly smooth and strictly convex Banach space $E$ with the Kadec-Klee property. Let $\left\{T_{i}\right\}_{i=1}^{\infty}: C \rightarrow C$ be an infinite family of closed and uniformly quasi- $\phi$-asymptotically nonexpansive mappings in the intermediate sense and for each $i \geq 1$, let $T_{i}$ be uniformly $L_{i}$-Lipschitzian continuous. $\left\{x_{n}\right\}$ is defined by

$$
\left\{\begin{array}{l}
x_{0} \in C \quad \text { chosen arbitrarily, } \quad C_{0}=C, \\
\left.y_{n}=J^{-1}\left(\alpha_{n} J x_{0}+\left(1-\alpha_{n}\right)\right) z_{n}\right), \\
z_{n}=J^{-1}\left(\beta_{n, 0} J x_{n}+\sum_{i=1}^{\infty} \beta_{n, j} J T_{i}^{n} x_{n}\right), \\
C_{n+1}=\left\{v \in C_{n}: \phi\left(v, y_{n}\right) \leq \alpha_{n} \phi\left(v, x_{0}\right)+\left(1-\alpha_{n}\right) \phi\left(v, x_{n}\right)+\xi_{n}\right\} \\
x_{n+1}=\prod_{C_{n+1}} x_{0}, \quad n \geq 0,
\end{array}\right.
$$

where $\xi_{n}=\max \left\{0, \sup _{p \in \bigcap_{i=1}^{\infty} F\left(T_{i}\right), x \in C}\left(\phi\left(p, T_{i}^{n} x\right)-\phi(p, x)\right)\right\}, \Pi_{C_{n+1}}$ is the generalized projection of $E$ onto $C_{n+1},\left\{\beta_{n, 0}, \beta_{n, i}\right\}$ and $\left\{\alpha_{n}\right\}$ are sequences in $[0,1]$ satisfying the following conditions:

(1) for each $n \geq 0, \beta_{n, 0}+\sum_{i=1}^{\infty} \beta_{n, i}=1$;

(2) $\liminf _{n \rightarrow \infty} \beta_{n, 0} \beta_{n, i}>0$ for any $i \geq 1$;

(3) $0 \leq \alpha_{n} \leq \alpha<1$ for some $\alpha \in(0,1)$. 
If $\bigcap_{i=1}^{\infty} F\left(T_{i}\right)$ is a nonempty and bounded subset of $C$, then the sequence $\left\{x_{n}\right\}$ converges strongly to $p \in \bigcap_{i=1}^{\infty} F\left(T_{i}\right)$, where $p=\Pi_{\bigcap_{i=1}^{\infty} F\left(T_{i}\right)} x_{0}$.

Proof We shall divide the proof into six steps.

Step 1. We show that $\bigcap_{i=1}^{\infty} F\left(T_{i}\right)$ and $C_{n}$ are closed and convex for each $n \geq 0$.

Using the similar methods given in the proof of Theorem 3.1 by Qin and Wang [17], the conclusion that $F\left(T_{i}\right)$ is closed and convex subset of $C$ for each $i \geq 1$ can be easily obtained. Therefore $\bigcap_{i=1}^{\infty} F\left(T_{i}\right)$ is closed and convex in $C$.

Again, by the assumption, $C_{0}=C$ is closed and convex. Suppose that $C_{n}$ is closed and convex for some $n \geq 1$. Since for any $z \in C_{n}$, we know

$$
\begin{gathered}
\phi\left(z, y_{n}\right) \leq \alpha_{n} \phi\left(z, x_{0}\right)+\left(1-\alpha_{n}\right) \phi\left(z, x_{n}\right)+\xi_{n} \\
\Leftrightarrow \quad 2 \alpha_{n}\left\langle z, J x_{0}\right\rangle+2\left(1-\alpha_{n}\right)\left\langle z, J x_{n}\right\rangle-2\left\langle z, J y_{n}\right\rangle \\
\leq \alpha_{n}\left\|x_{0}\right\|^{2}+\left(1-\alpha_{n}\right)\left\|x_{n}\right\|^{2}-\left\|y_{n}\right\|^{2}+\xi_{n} .
\end{gathered}
$$

Hence the set $C_{n+1}=\left\{z \in C_{n}: 2 \alpha_{n}\left\langle z, J x_{0}\right\rangle+2\left(1-\alpha_{n}\right)\left\langle z, J x_{n}\right\rangle-2\left\langle z, J y_{n}\right\rangle \leq \alpha_{n}\left\|x_{0}\right\|^{2}+(1-\right.$ $\left.\left.\alpha_{n}\right)\left\|x_{n}\right\|^{2}-\left\|y_{n}\right\|^{2}+\xi_{n}\right\}$ is closed and convex. Therefore $\Pi_{C_{n}} x_{0}$ and $\Pi_{\bigcap_{i=1}^{\infty} F\left(T_{i}\right)} x_{0}$ are well defined.

Step 2. We show that $\bigcap_{i=1}^{\infty} F\left(T_{i}\right) \subset C_{n}$ for all $n \geq 0$.

It is obvious that $\bigcap_{i=1}^{\infty} F\left(T_{i}\right) \subset C_{0}=C$. Suppose that $\bigcap_{i=1}^{\infty} F\left(T_{i}\right) \subset C_{n}$ for some $n \geq 1$. Since $E$ is uniformly smooth, $E^{*}$ is uniformly convex. For any given $q \in \bigcap_{i=1}^{\infty} F\left(T_{i}\right) \subset C_{n}$, we observe that

$$
\begin{aligned}
\phi\left(q, y_{n}\right) & =\phi\left(q, J^{-1}\left(\alpha_{n} J x_{0}+\left(1-\alpha_{n}\right) J z_{n}\right)\right) \\
& =\|q\|^{2}-2\left\langle q, \alpha_{n} J x_{0}+\left(1-\alpha_{n}\right) J z_{n}\right\rangle+\left\|\alpha_{n} J x_{0}+\left(1-\alpha_{n}\right) J z_{n}\right\|^{2} \\
& \leq\|q\|^{2}-2 \alpha_{n}\left\langle q, J x_{0}\right\rangle-2\left(1-\alpha_{n}\right)\left\langle q, J z_{n}\right\rangle+\alpha_{n}\left\|x_{0}\right\|^{2}+\left(1-\alpha_{n}\right)\left\|z_{n}\right\|^{2} \\
& =\alpha_{n} \phi\left(q, x_{0}\right)+\left(1-\alpha_{n}\right) \phi\left(q, z_{n}\right) .
\end{aligned}
$$

On the other hand, it follows from Lemma 2.3 that for any positive integer $l>1$ and for any $q \in \bigcap_{i=1}^{\infty} F\left(T_{i}\right)$, we have

$$
\begin{aligned}
\phi\left(q, z_{n}\right)= & \phi\left(q, J^{-1}\left(\beta_{n, 0} J x_{n}+\sum_{i=1}^{\infty} \beta_{n, i} J T_{i}^{n} x_{n}\right)\right) \\
= & \|q\|^{2}-2\left\langle q, \beta_{n, 0} J x_{n}+\sum_{i=1}^{\infty} \beta_{n, i} J T_{i}^{n} x_{n}\right\rangle+\left\|\beta_{n, 0} J x_{n}+\sum_{i=1}^{\infty} \beta_{n, i} J T_{i}^{n} x_{n}\right\|^{2} \\
\leq & \|q\|^{2}-2 \beta_{n, 0}\left\langle q, J x_{n}\right\rangle-2 \sum_{i=1}^{\infty} \beta_{n, i}\left\langle q, J T_{i}^{n} x_{n}\right\rangle+\beta_{n, 0}\left\|x_{n}\right\|^{2} \\
& +\sum_{i=1}^{\infty} \beta_{n, i}\left\|T_{i}^{n} x_{n}\right\|^{2}-\beta_{n, 0} \beta_{n, l} g\left(\left\|J x_{n}-J T_{l}^{n} x_{n}\right\|\right) \\
= & \beta_{n, 0} \phi\left(q, x_{n}\right)+\sum_{i=1}^{\infty} \beta_{n, i} \phi\left(q, T_{i}^{n} x_{n}\right)-\beta_{n, 0} \beta_{n, l} g\left(\left\|J x_{n}-J T_{l}^{n} x_{n}\right\|\right)
\end{aligned}
$$




$$
\begin{aligned}
& \leq \beta_{n, 0} \phi\left(q, x_{n}\right)+\sum_{i=1}^{\infty} \beta_{n, i}\left\{\phi\left(q, x_{n}\right)+\xi_{n}\right\}-\beta_{n, 0} \beta_{n, l} g\left(\left\|J x_{n}-J T_{l}^{n} x_{n}\right\|\right) \\
& \leq \phi\left(q, x_{n}\right)+\xi_{n}-\beta_{n, 0} \beta_{n, l} g\left(\left\|J x_{n}-J T_{l}^{n} x_{n}\right\|\right) .
\end{aligned}
$$

Substituting (3.4) into (3.3), we get

$$
\begin{aligned}
\phi\left(q, y_{n}\right) & \leq \alpha_{n} \phi\left(q, x_{0}\right)+\left(1-\alpha_{n}\right) \phi\left(q, z_{n}\right) \\
& \leq \alpha_{n} \phi\left(q, x_{0}\right)+\left(1-\alpha_{n}\right)\left[\phi\left(q, x_{n}\right)+\xi_{n}-\beta_{n, 0} \beta_{n, l} g\left(\left\|J x_{n}-J T_{l}^{n} x_{n}\right\|\right)\right] \\
& \leq \alpha_{n} \phi\left(q, x_{0}\right)+\left(1-\alpha_{n}\right) \phi\left(q, x_{n}\right)+\xi_{n} .
\end{aligned}
$$

This shows that $q \in C_{n+1}$. Further this implies that $\bigcap_{i=1}^{\infty} F\left(T_{i}\right) \subset C_{n+1}$ and hence $\bigcap_{i=1}^{\infty} F\left(T_{i}\right) \subset C_{n}$ for all $n \geq 0$. Since $\bigcap_{i=1}^{\infty} F\left(T_{i}\right)$ is nonempty, $C_{n}$ is a nonempty closed convex subset of $E$ and hence $\Pi_{C_{n}}$ exists for all $n \geq 0$. This implies that the sequence $\left\{x_{n}\right\}$ is well defined.

Step 3. We show that $\left\{x_{n}\right\}$ is bounded and $\left\{\phi\left(x_{n}, x_{0}\right)\right\}$ is a convergent sequence.

It follows from (3.1) and Lemma 2.2 that

$$
\begin{aligned}
\phi\left(x_{n}, x_{0}\right) & =\phi\left(\Pi_{C_{n}} x_{0}, x_{0}\right) \\
& \leq \phi\left(p, x_{0}\right)-\phi\left(p, x_{n}\right) \\
& \leq \phi\left(p, x_{0}\right), \quad \forall p \in C_{n+1}, \forall n \geq 0 .
\end{aligned}
$$

From the definition of $C_{n+1}$ that $x_{n}=\Pi_{C_{n}} x_{0}$ and $x_{n+1}=\Pi_{C_{n+1}} x_{0}$, we have

$$
\phi\left(x_{n}, x_{0}\right) \leq \phi\left(x_{n+1}, x_{0}\right), \quad \forall n \geq 0 .
$$

Therefore, $\left\{\phi\left(x_{n}, x_{0}\right)\right\}$ is nondecreasing and bounded. So, $\left\{\phi\left(x_{n}, x_{0}\right)\right\}$ is a convergent sequence, without loss of generality, we can assume that $\lim _{n \rightarrow \infty} \phi\left(x_{n}, x_{0}\right)=d \geq 0$. In particular, by (1.3), the sequence $\left\{\left(\left\|x_{n}\right\|-\left\|x_{0}\right\|\right)^{2}\right\}$ is bounded. This implies $\left\{x_{n}\right\}$ is also bounded.

Step 4 . We prove that $\left\{x_{n}\right\}$ converges strongly to some point $p \in C$.

Since $\left\{x_{n}\right\}$ is bounded and $E$ is reflective, there exists a subsequence $\left\{x_{n_{i}}\right\} \subset\left\{x_{n}\right\}$ such that $x_{n_{i}} \rightarrow p$ (some point in $C$ ). Since $C_{n}$ is closed and convex and $C_{n+1} \subset C_{n}$, this implies that $C_{n}$ is weakly closed and $p \in C_{n}$ for each $n \geq 0$. From $x_{n_{i}}=\Pi_{C_{n_{i}}} x_{0}$, we have

$$
\phi\left(x_{n_{i}}, x_{0}\right) \leq \phi\left(p, x_{0}\right), \quad \forall n_{i} \geq 0
$$

Since the norm $\|\cdot\|$ is weakly lower semi-continuous, we have

$$
\begin{aligned}
\liminf _{n_{i} \rightarrow \infty} \phi\left(x_{n_{i}}, x_{0}\right) & =\liminf _{n_{i} \rightarrow \infty}\left\{\left\|x_{n_{i}}\right\|^{2}-2\left\langle x_{n_{i}}, J x_{0}\right\rangle+\left\|x_{0}\right\|^{2}\right\} \\
& \geq\|p\|^{2}-2\left\langle p, J x_{0}\right\rangle+\left\|x_{0}\right\|^{2} \\
& =\phi\left(p, x_{0}\right),
\end{aligned}
$$

and so

$$
\phi\left(p, x_{0}\right) \leq \liminf _{n_{i} \rightarrow \infty} \phi\left(x_{n_{i}}, x_{0}\right) \leq \limsup _{n_{i} \rightarrow \infty} \phi\left(x_{n_{i}}, x_{0}\right) \leq \phi\left(p, x_{0}\right) .
$$


This implies that $\lim _{n_{i} \rightarrow \infty} \phi\left(x_{n_{i}}, x_{0}\right) \rightarrow \phi\left(p, x_{0}\right)$, and so $\left\|x_{n}\right\| \rightarrow\|p\|$. Since $x_{n_{i}} \rightarrow p$, in view of the Kadec-Klee property of $E$, it follows that

$$
\lim _{n_{i} \rightarrow \infty} x_{n_{i}}=p
$$

Since $\left\{\phi\left(x_{n}, x_{0}\right)\right\}$ is convergent, this together with $\lim _{n_{i} \rightarrow \infty} \phi\left(x_{n_{i}}, x_{0}\right) \rightarrow \phi\left(p, x_{0}\right)$, we have $\lim _{n \rightarrow \infty} \phi\left(x_{n}, x_{0}\right) \rightarrow \phi\left(p, x_{0}\right)$. If there exists a subsequence $\left\{x_{n_{j}}\right\} \subset\left\{x_{n}\right\}$ such that $x_{n_{j}} \rightarrow q$, then from Lemma 2.2(a), we have that

$$
\begin{aligned}
\phi(p, q) & =\lim _{n_{i}, n_{j} \rightarrow \infty} \phi\left(x_{n_{i}}, x_{n_{j}}\right) \\
& =\lim _{n_{i}, n_{j} \rightarrow \infty} \phi\left(x_{n_{i}}, \Pi_{C_{n_{j}}} x_{0}\right) \\
& \leq \lim _{n_{i}, n_{j} \rightarrow \infty}\left(\phi\left(x_{n_{i}}, x_{0}\right)-\phi\left(\Pi_{C_{n_{j}}} x_{0}, x_{0}\right)\right) \\
& =\lim _{n_{i}, n_{j} \rightarrow \infty}\left(\phi\left(x_{n_{i}}, x_{0}\right)-\phi\left(x_{n_{i}}, x_{0}\right)\right) \\
& =\phi\left(p, x_{0}\right)-\phi\left(p, x_{0}\right) \\
& =0 .
\end{aligned}
$$

This implies that $p=q$ and

$$
\lim _{n \rightarrow \infty} x_{n}=p
$$

Step 5. We show that $p \in \bigcap_{i=1}^{\infty} F\left(T_{i}\right)$.

Since $x_{n+1} \in C_{n+1}$, it follows from (3.1) and (3.13) that

$$
\phi\left(x_{n+1}, y_{n}\right) \leq \alpha_{n} \phi\left(x_{n+1}, x_{0}\right)+\left(1-\alpha_{n}\right) \phi\left(x_{n+1}, x_{n}\right)+\xi_{n} \rightarrow 0 \quad(\text { as } n \rightarrow \infty) .
$$

Since $x_{n} \rightarrow p$, by Lemma 2.1

$$
\lim _{n \rightarrow \infty} y_{n}=p
$$

By (3.3) and (3.4), for any $q \in \bigcap_{i=1}^{\infty} F\left(T_{i}\right)$, we have

$$
\phi\left(q, y_{n}\right) \leq \alpha_{n} \phi\left(q, x_{0}\right)+\left(1-\alpha_{n}\right) \phi\left(q, x_{n}\right)+\xi_{n}-\left(1-\alpha_{n}\right) \beta_{n, 0} \beta_{n, l} g\left(\left\|J x_{n}-J T_{l}^{n} x_{n}\right\|\right) .
$$

So, as $n \rightarrow \infty$,

$$
\begin{aligned}
\left(1-\alpha_{n}\right) \beta_{n, 0} \beta_{n, l} g\left\|J x_{n}-J T_{l}^{n} x_{n}\right\| & \leq \alpha_{n} \phi\left(q, x_{0}\right)+\left(1-\alpha_{n}\right) \phi\left(q, x_{n}\right)+\xi_{n}-\phi\left(q, y_{n}\right) \\
& \rightarrow 0 .
\end{aligned}
$$

Therefore,

$$
\lim _{n \rightarrow \infty}\left(1-\alpha_{n}\right) \beta_{n, 0} \beta_{n, l} g\left\|J x_{n}-J T_{l}^{n} x_{n}\right\|=0 .
$$


In view of the property of $g$, we have

$$
\left\|J x_{n}-J T_{l}^{n} x_{n}\right\| \rightarrow 0 \quad(\text { as } n \rightarrow \infty)
$$

Since $J x_{n} \rightarrow J p$, this implies that $\lim _{n \rightarrow \infty} J T_{l}^{n} x_{n}=J p$. Remark 1.1(ii) yields

$$
T_{l}^{n} x_{n} \rightarrow p \quad(\text { as } n \rightarrow \infty)
$$

Again, since

$$
\left\|T_{l}^{n} x_{n}\right\|-\|p\|=\left\|J\left(T_{l}^{n} x_{n}\right)\right\|-\|J p\| \leq\left\|J\left(T_{l}^{n} x_{n}\right)-J p\right\| \rightarrow 0 \quad(\text { as } n \rightarrow \infty),
$$

this together with (3.20) and the Kadec-Klee property of $E$ shows that

$$
\lim _{n \rightarrow \infty} T_{l}^{n} x_{n}=p
$$

By the assumption that $T_{l}$ is uniformly $L_{l}$-Lipschitz continuous, we have

$$
\begin{aligned}
\left\|T_{l}^{n+1} x_{n}-T_{l}^{n} x_{n}\right\| \leq & \left\|T_{l}^{n+1} x_{n}-T_{l}^{n+1} x_{n+1}\right\|+\left\|T_{l}^{n+1} x_{n+1}-x_{n+1}\right\| \\
& +\left\|x_{n+1}-x_{n}\right\|+\left\|x_{n}-T_{l}^{n} x_{n}\right\| \\
\leq & \left(L_{l}+1\right)\left\|x_{n+1}-x_{n}\right\|+\left\|T_{l}^{n+1} x_{n+1}-x_{n+1}\right\|+\left\|x_{n}-T_{l}^{n} x_{n}\right\| .
\end{aligned}
$$

This together with (3.21) and $x_{n} \rightarrow p$ shows that $\lim _{n \rightarrow \infty}\left\|T_{l}^{n+1} x_{n}-T_{l}^{n} x_{n}\right\|=0$ and $\lim _{n \rightarrow \infty} T_{l}^{n+1} x_{n}=p$, that is, $\lim _{n \rightarrow \infty} T_{l} T_{l}^{n} x_{n}=p$. In view of the closeness of $T_{l}$, it follows that $T_{l} p=p$, that is, $p \in F\left(T_{l}\right)$. By the arbitrariness of $l \geq 1$, we have $p \in \bigcap_{i=1}^{\infty} F\left(T_{i}\right)$.

Step 6. We prove that $x_{n} \rightarrow p=\Pi_{\bigcap_{i=1}^{\infty} F\left(T_{i}\right)} x_{0}$.

Let $q=\Pi_{\bigcap_{i=1}^{\infty} F\left(T_{i}\right)} x_{0}$. From $x_{n}=\Pi_{C_{n}} x_{0}$ and $q \in \bigcap_{i=1}^{\infty} F\left(T_{i}\right) \subset C_{n}$, we have

$$
\phi\left(x_{n}, x_{0}\right) \leq \phi\left(q, x_{0}\right), \quad \forall n \geq 0
$$

This implies that

$$
\phi\left(p, x_{0}\right)=\lim _{n \rightarrow \infty} \phi\left(x_{n}, x_{0}\right) \leq \phi\left(q, x_{0}\right) .
$$

By the definition of $p=\Pi_{\bigcap_{i=1}^{\infty} F\left(T_{i}\right)} x_{0}$, we have $p=q$. Therefore, $x_{n} \rightarrow p=\Pi_{\bigcap_{i=1}^{\infty} F\left(T_{i}\right)} x_{0}$. This completes the proof.

In Theorem 3.1, as $T_{i}=T$ for each $i \in N$, we can obtain the following corollary.

Corollary 3.2 Let $C$ be a nonempty, closed and convex subset of a uniformly smooth and strictly convex Banach space $E$ with the Kadec-Klee property. Let $T: C \rightarrow C$ be a closed uniformly L-Lipschitzian continuous and uniformly quasi- $\phi$-asymptotically nonexpansive 
mapping in the intermediate sense such that $F(T)$ is a nonempty and bounded subset of $C$. Let $\left\{x_{n}\right\}$ be a sequence generated by

$$
\left\{\begin{array}{l}
x_{0} \in C \quad \text { chosen arbitrarily, } \quad C_{0}=C, \\
\left.y_{n}=J^{-1}\left(\alpha_{n} J x_{0}+\left(1-\alpha_{n}\right)\right) z_{n}\right), \\
z_{n}=J^{-1}\left(\beta_{n} J x_{n}+\left(1-\beta_{n}\right) J T^{n} x_{n}\right), \\
C_{n+1}=\left\{v \in C_{n}: \phi\left(v, y_{n}\right) \leq \alpha_{n} \phi\left(v, x_{0}\right)+\left(1-\alpha_{n}\right) \phi\left(v, x_{n}\right)+\xi_{n}\right\}, \\
x_{n+1}=\Pi_{C_{n+1}} x_{0}, \quad n \geq 0,
\end{array}\right.
$$

where $\xi_{n}=\max \left\{0, \sup _{p \in F(T), x \in C}\left(\phi\left(p, T^{n} x\right)-\phi(p, x)\right)\right\}, \Pi_{C_{n+1}}$ is the generalized projection of E onto $C_{n+1},\left\{\alpha_{n}\right\}$ is a sequence in $[0, \alpha],\left\{\beta_{n}\right\} \subset(0,1)$ satisfies that $\liminf _{n \rightarrow \infty} \beta_{n}\left(1-\beta_{n}\right)>0$, then the sequence $\left\{x_{n}\right\}$ converges strongly to $p \in F(T)$, where $p=\Pi_{F(T)} x_{0}$.

Corollary 3.3 Let $C$ be a nonempty, closed and convex subset of a uniformly smooth and strictly convex Banach space $E$ with the Kadec-Klee property. Let $\left\{T_{i}\right\}_{i=1}^{\infty}: C \rightarrow C$ be an infinite family of closed and uniformly quasi- $\phi$-asymptotically nonexpansive mappings in the intermediate sense and for each $i \geq 1, T_{i}$ is uniformly $L_{i}$-Lipschitzian continuous. $\left\{x_{n}\right\}$ is defined by

$$
\left\{\begin{array}{l}
x_{0} \in C \quad \text { chosen arbitrarily, } \quad C_{0}=C, \\
z_{n}=J^{-1}\left(\beta_{n, 0} J x_{n}+\sum_{i=1}^{\infty} \beta_{n, j} J T_{i}^{n} x_{n}\right), \\
C_{n+1}=\left\{v \in C_{n}: \phi\left(v, y_{n}\right) \leq \phi\left(v, x_{n}\right)+\xi_{n}\right\}, \\
x_{n+1}=\Pi_{C_{n+1} x_{0}}, \quad n \geq 0,
\end{array}\right.
$$

where $\xi_{n}=\max \left\{0, \sup _{p \in \bigcap_{i=1}^{\infty} F\left(T_{i}\right), x \in C}\left(\phi\left(p, T_{i}^{n} x\right)-\phi(p, x)\right)\right\}, \Pi_{C_{n+1}}$ is the generalized projection of E onto $C_{n+1},\left\{\beta_{n, 0}, \beta_{n, i}\right\}$ and $\left\{\alpha_{n}\right\}$ are sequences in $[0,1]$ satisfying the following conditions:

(1) for each $n \geq 0 \beta_{n, 0}+\sum_{i=1}^{\infty} \beta_{n, i}=1$;

(2) $\liminf _{n \rightarrow \infty} \beta_{n, 0} \beta_{n, i}>0$ for any $i \geq 1$;

(3) $0 \leq \alpha_{n} \leq \alpha<1$ for some $\alpha \in(0,1)$.

If $\bigcap_{i=1}^{\infty} F\left(T_{i}\right)$ is a nonempty and bounded subset of $C$, then the sequence $\left\{x_{n}\right\}$ converges strongly to $p \in \bigcap_{i=1}^{\infty} F\left(T_{i}\right)$, where $p=\Pi_{\bigcap_{i=1}^{\infty} F\left(T_{i}\right)} x_{0}$.

Proof Setting $\alpha_{n} \equiv 0$ in Theorem 3.1, then we get that $y_{n}=z_{n}$. Thus, from the method of the proof of Theorem 3.1, we obtain Corollary 3.3 immediately.

In the Hilbert space, the following corollary can be directly obtained from Theorem 3.1.

Corollary 3.4 Let $C$ be a nonempty, closed and convex subset of a Hilbert space E. Let $\left\{T_{i}\right\}_{i=1}^{\infty}: C \rightarrow C$ be an infinite family of closed and uniformly $L_{i}$-Lipschitzian continuous and uniformly asymptotically quasi-nonexpansive mappings in the intermediate sense such that $\bigcap_{i=1}^{\infty} F\left(T_{i}\right)$ is a nonempty and bounded subset of C. Let $\left\{x_{n}\right\}$ be the sequence generated 
by

$$
\left\{\begin{array}{l}
x_{0} \in C \quad \text { chosen arbitrarily, } \quad C_{0}=C, \\
y_{n}=\alpha_{n} x_{0}+\left(1-\alpha_{n}\right) z_{n}, \\
z_{n}=\beta_{n, 0} x_{n}+\sum_{i=1}^{\infty} \beta_{n, i} T_{i}^{n} x_{n}, \\
C_{n+1}=\left\{v \in C_{n}:\left\|v-y_{n}\right\|^{2} \leq \alpha_{n}\left\|v-x_{0}\right\|^{2}+\left(1-\alpha_{n}\right)\left\|v-x_{n}\right\|^{2}+\xi_{n}\right\}, \\
x_{n+1}=P_{C_{n+1}} x_{0}, \quad n \geq 0,
\end{array}\right.
$$

where $\xi_{n}=\max \left\{0, \sup _{p \in \bigcap_{i=1}^{\infty} F\left(T_{i}\right), x \in C}\left(\left\|p-T_{i}^{n} x\right\|^{2}-\|p-x\|^{2}\right)\right\}, P_{C_{n+1}}$ is the metric projection of $E$ onto $C_{n+1},\left\{\beta_{n, 0}, \beta_{n, i}\right\}$ and $\left\{\alpha_{n}\right\}$ are sequences in $[0,1]$ satisfying the following conditions:

(1) for each $n \geq 0 \beta_{n, 0}+\sum_{i=1}^{\infty} \beta_{n, i}=1$;

(2) $\liminf _{n \rightarrow \infty} \beta_{n, 0} \beta_{n, i}>0$ for any $i \geq 1$;

(3) $0 \leq \alpha_{n} \leq \alpha<1$ for some $\alpha \in(0,1)$.

Then the sequence $\left\{x_{n}\right\}$ converges strongly to $p \in \bigcap_{i=1}^{\infty} F\left(T_{i}\right)$, where $p=\Pi_{\bigcap_{i=1}^{\infty} F\left(T_{i}\right)} x_{0}$.

\section{Competing interests}

The authors declare that they have no competing interests.

\section{Authors' contributions}

All authors contributed equally and significantly in writing this paper. All authors read and approved the final manuscript.

\section{Author details}

'School of Information Engineering, The College of Arts and Sciences, Yunnan Normal University, Kunming, Yunnan 650222, P.R. China. ${ }^{2}$ College of Statistics and Mathematics, Yunnan University of Finance and Economics, Kunming, Yunnan 650021, P.R. China.

\section{Acknowledgements}

This work was supported by the Natural Scientific Research Foundation of Yunnan Province (Grant No. 2011FB074).

\section{Received: 15 February 2013 Accepted: 30 May 2013 Published: 3 July 2013}

\section{References}

1. Cioranescu, I: Geometry of Banach Spaces, Duality Mappings and Nonlinear Problems. Kluwer Academic, Dordrecht (1990)

2. Takahashi, W: Nonlinear Functional Analysis. Yokohama Publishers, Yokohama (2000)

3. Alber, YI: Metric and generalized projection operators in Banach spaces: properties and applications. In: Kartsatos, AG (ed.) Theory and Applications of Nonlinear Operators of Accretive and Monotonic Type, pp. 15-50. Dekker, New York (1996)

4. Alber, Yl, Reich, S: An iterative method for solving a class of nonlinear operator equations in Banach spaces. Panam. Math. J. 4(2), 39-54 (1994)

5. Kamimura, S, Takahashi, W: Strong convergence of a proximal-type algorithm in Banach space. SIAM J. Optim. 13, 938-945 (2002)

6. Goebel, K, Kirk, WA: A fixed point theorem for asymptotically nonexpansive mappings. Proc. Am. Math. Soc. 35, 171-174 (1972)

7. Reich, S: A weak convergence theorem for the alternating method with Bregman distance. In: Kartsatos, AG (ed.) Theory and Applications of Nonlinear Operators of Accretive and Monotonic Type, pp. 313-318. Dekker, New York (1996)

8. Nilsrakoo, W, Saejung, S: Strong convergence to common fixed points of countable relatively quasi-nonexpansive mappings. Fixed Point Theory Appl. 2008, Article ID 312454 (2008)

9. Su, Y, Wang, D, Shang, M: Strong convergence of monotone hybrid algorithm for hemi-relatively nonexpansive mappings. Fixed Point Theory Appl. 2008, Article ID 284613 (2008)

10. Zegeye, H, Shahzad, N: Strong convergence for monotone mappings and relatively weak nonexpansive mappings. Nonlinear Anal. 70, 2707-2716 (2009)

11. Butnariu, D, Reich, S, Zaslavski, AJ: Asymptotic behavior of relatively nonexpansive operators in Banach spaces. J. Appl. Anal. 7, 151-174 (2001)

12. Butnariu, D, Reich, S, Zaslavski, AJ: Weak convergence of orbits of nonlinear operators in reflexive Banach spaces. Numer. Funct. Anal. Optim. 24, 489-508 (2003)

13. Censor, Y, Reich, S: Iterations of paracontractions and firmly nonexpansive operators with applications to feasibility and optimization. Optimization 37, 323-339 (1996)

14. Matsushita, S, Takahashi, W: A strong convergence theorem for relatively nonexpansive mappings in a Banach space. J. Approx. Theory 134, 257-266 (2005) 
15. Saewan, S, Kumam, P, Wattanawitoon, K: Convergence theorem based on a new hybrid projection method for finding a common solution of generalized equilibrium and variational inequality problems in Banach spaces. Abstr. Appl. Anal. 2010, Article ID 734126 (2010)

16. Bruck, RE, Kuczumow, T, Reich, S: Convergence of iterates of asymptotically nonexpansive mappings in Banach spaces with the uniform Opial property. Colloq. Math. 65, 169-179 (1993)

17. Qin, $X \mathrm{~L}$, Wang, L: On asymptotically quasi- $\boldsymbol{\phi}$-nonexpansive mappings in the intermediate sense. Abstr. Appl. Anal. 2012, Article ID 636217 (2012)

18. Chidume, CE, Shahzad, N, Zegeye, H: Convergence theorems for mappings which are asymptotically nonexpansive in the intermediate sense. Numer. Funct. Anal. Optim. 25, 239-257 (2004)

19. Kim, GE, Kim, TH: Mann and Ishikawa iterations with errors for non-Lipschitzian mappings in Banach spaces. Comput. Math. Appl. 42, 1565-1570 (2001)

20. Mann, WR: Mean value methods in iteration. Proc. Am. Math. Soc. 4, 506-510 (1953)

21. Genel, A, Lindenstrauss, J: An example concerning fixed points. Isr. J. Math. 22, 81-86 (1975)

22. Halpern, B: Fixed points of nonexpansive maps. Bull. Am. Math. Soc. 73, 957-961 (1967)

23. Nilsrakoo, W, Saejung, S: Strong convergence theorems by Halpern-Mann iterations for relatively nonexpansive mappings in Banach spaces. Appl. Math. Comput. 217, 6577-6586 (2011)

24. Chang, SS, Chan, CK, Lee, HWJ: Modified block iterative algorithm for quasi- $\phi$-asymptotically nonexpansive mappings and equilibrium problem in Banach spaces. Appl. Math. Comput. 217, 7520-7530 (2011)

25. Liu, ZQ, Kang, SM: Weak and strong convergence for fixed points of asymptotically nonexpansive mappings. Acta Math. Sin. 20, 1009-1018 (2004)

26. Qin, X, Cho, SY, Kang, SM: Strong convergence of shrinking projection methods for quasi- $\phi$-nonexpansive mappings and equilibrium problems. J. Comput. Appl. Math. 234(3), 750-760 (2010)

27. Zhou, H, Gao, G, Tan, B: Convergence theorems of a modified hybrid algorithm for a family of quasi- $\phi$-asymptotically nonexpansive mappings. J. Appl. Math. Comput. 32, 453-464 (2010)

28. Qin, X, Cho, YJ, Kang, SM, Zhu, H: Convergence of a modified Halpern-type iteration algorithm for quasi- $\phi$-nonexpansive mappings. Appl. Math. Lett. 22, 1051-1055 (2009)

29. Ye, J, Huang, J: Strong convergence theorems for fixed point problems and generalized equilibrium problems of three relatively quasi-nonexpansive mappings in Banach spaces. J. Math. Comput. Sci. 1, 1-18 (2011)

30. Chang, SS, Lee, HWJ, Chan, CK, Yang, L: Approximation theorems for total quasi- $\boldsymbol{\phi}$-asymptotically nonexpansive mappings with applications. Appl. Math. Comput. 218, 2921-2931 (2011)

31. Chang, SS, Kim, JK, Wang, XR: Modified block iterative algorithm for solving convex feasibility problems in Banach spaces. J. Inequal. Appl. 2010, Article ID 869684 (2010)

doi:10.1186/1029-242X-2013-306

Cite this article as: Ma et al.: Strong convergence theorem for quasi- $\phi$-asymptotically nonexpansive mappings in the intermediate sense in Banach spaces. Journal of Inequalities and Applications 2013 2013:306.

\section{Submit your manuscript to a SpringerOpen ${ }^{\ominus}$ journal and benefit from:}

- Convenient online submission

- Rigorous peer review

- Immediate publication on acceptance

- Open access: articles freely available online

- High visibility within the field

- Retaining the copyright to your article 